\title{
Online and Face to Face Composition in the Various Types of Learning Style
}

\author{
Hamonangan Tambunan ${ }^{1 *}$, Marsangkap Silitonga ${ }^{1}$, Nelson Sinaga $^{1}$ \\ \{*hamonangantambunan@unimed.ac.id, marsangkap@unimed.ac.id,nel7naga@gmail.com \} \\ Electrical Engineering Education Program, Universitas Negeri Medan, North Sumatra, Indonesia ${ }^{1}$
}

\begin{abstract}
The experiments have been conducted on electro technical teaching for ensuring the most suitable combination of online learning and face-to-face in blended learning on the certain type of learning style. There were 166 participants involved and scattered in five groups. The full online (OL) and full face to face (F2F) were control groups, and there were three combinations of online and face to face in different forms made, namely 25-75, 50-50, and 75-25 OL-F2F. The Learning Style Questionnaire and Electro technical Competencies Test were used in tracing the participants' learning styles and testing their competence. The 2-Way Anova, Sig. 0,05 shown the group of theorist and pragmatist learning style were better learned by the same OL-F2F composition, while the activist and reflector style were by the 75-25 and 25-75 of OL-F2F composition respectively.
\end{abstract}

Keywords: Online, face to face, learning style

\section{Introduction}

The optimal learning outcomes are the main goals in all of the learning activities, therefore It always be chosen the most suitable approach [1]. Based on their implementation, the learning form can be dinguished in three approaches. The first one is the online learning, which is the fully utilizing information and communication technology [2][1][4]. The second is the face-to-face learning, which is commonly called the traditional learning[5]. The third is the combination of the online and face to face, which is called the blended learning [6][7]. It's stated the online learning has the superiority because the learners can learn individually anywhere, anytime and offers immediate access to specific information [8];[2];[10];[11].

In general, the students have diverse backgrounds, so their characteristics are also different in speed and strength in learning. In the other side, the face to face learning is also superior in the specific fields especially in mentoring for the weak students [12]. The teacher plays a more active role in this learning. Based on their advantage and disadvantage, combining the two of them can become a promising form because the traditional learning can be supported by web based on-line approaches. It has been stated that one way to integrate is to make computer-mediated and face to face learning activities overlap in time [3]. The media and the tools are employed in an e-learning environment with a number of pedagogic approaches, and irrespective of the learning technology used[14]. It is possible to provide several benefits including to increase the perception and discipline on the learning[15][16], to form the learning autonomy through involvement in deep learning [17]. The chance to collaborate are open, so who are the weaker can get help from those who are more skilled [4]. 
As well as the resources utilized and the important problems from institutions can also to be overcome [5];[20]. The organically technologies integrated in this learning, can complement the face-to-face approach through online methods. So the delivery, the teaching models the learning styles play an important role in these learning environments [6]. Providing the wider students' discussion opportunities in increasing the sutdents' understanding can be done by making the different learning approach [7]; [8];[24]. It can also enhance the learning motivation and satisfaction which have a positive impact on the learning outcomes [9]; [10];[27];[28];[11].

So far It was claimed that the learning outcomes can be obtained well through the blended learning [12];[31];[32], but there is only a few explanations of the learning styles types different role and the most suitable composition of the online and face-to-face learning in the blended learning. Although the learning style different is recommended not to be disseminated [13], but based on daily experience, it is very important to consider when doing learning so that it can provide more optimal results, especially to use a particular learning approach. The learning style type is divided into four types, namely activist, theorist, pragmatist, and reflector [34];[14], and the combination of the online and face-to-face learning is impossible made according to the needs [15]. The combination of blended forms with the certain types of learning styles that are most appropriate, is important to consider the learning approach needed, and to develop the certain intellectual level [37], and the different learning process [16]; [17];[40]. Thus the obstacles between the learning process in class, on campus, and network-based learning are eliminated, and the conditions of optimal learning experience can be formed [41]. In this paper we will describe the appropriate combination of online and face-to-face learning on electrotechnical blended learning, for different types of the learners learning styles.

\section{Methodology}

\subsection{Electrotechnical Competence in Blended Learning}

The knowledges, skills, and the other internal factors of individuals related in doing work, called competencies, are the main objective of the learning and training activities [42][18]. To be competent in the field of electrotechnics must understand the engineering sciences, engineering analysis and investigation, engineering design, and engineering practice [44]. Some complex things are learned in this case, so for these pupose, the dynamic models is required to form the understanding specific competencies, and critical reflections of the learner [45]. The learning that gives instructor and the learner the opportunity to interact during the learning process, is needed to form the positive student perceptions toward learning, the better processes and environment, and the information literacy components [46];[19];[20]. Also the cognitive control, cognitive style, learning style, initial ability of students, and the type of model chosen in learning to guarantee the success of learning, is important to be considered [21].

Combining the two separate paradigms, namely classrooms-synchronous, and onlineasynchronous is named as blended learning [22], which integrate and plan pedagogically the online and face-to-face learning. The part of the time of face-to-face activities can be replaced by online activities [23]. The combination of the two of them is impossible to acomodate the varities of learning characteristics [24]. In other word, the learning can be done in the classroom and at a distance, or using a mixture of different pedagogical strategies by (a) 
combining various pedagogical approaches such as constructivism, behaviorism, cognitive learning approaches to produce optimal learning outcomes with or without the use of instructional technology; (b) combining forms of instructional technology and web-based training with face to face where programming is led by instructors; and (c) mixing or combining instructional technology with actual work tasks to create a harmonious effect on learning and work (Gil and Garcia in [25]). The internet becomes a place for online learning, and instructional medium, which is incorporated into the learning media by integrating several delivery modalities both synchronous and asynchronous [54]. It is described that the learning, the media, and the instructional environments are the elements of the component unity of blended learning [26].

The synchronous and asynchronous learning, with their advantages and disadvantages, are included in the learning environment. The interaction between the teacher and the learner that occurs through face-to-face, is called a synchronous form, and the acronym is through online. The specific positive attributes of each environment are intended to ensure optimal use of resources in achieving the instructional goals and the learning goals. The media is needed as a tool to deliver content, which is possible in various forms with the different uses. This is becaused of no single media is inherently better or worse than others [27]. With the media, the instructors and the students are possible to continue for establishing the communication both directly and indirectly.

The shipping media used does not change the desired content because sometimes the presentation of learning that is offline can be managed through an online learning system [28]. This is intended to support the achievement of learning objectives so that the most appropriate learning strategy is chosen. Strategy is a product of learning objectives, namely to serve, ensure learning goals, and facilitate learning transfer. The synchronous teaching form is applied to traditional classes, virtual classrooms, direct product practice laboratories, interactive chatrooms and mentoring [29]. Live classroom and traditional classes provide opportunities for teachers and students to meet face-to-face in the same place for complex, broad, program or new content, which requires face-to-face interaction, expert observation, cultural formation, networking, problem solving or material will be presented by the teacher [30].

The obstacles in planning of learning is overcome by understanding the teaching, adjusting the best media with performance goals, maintaining the interactive online provision, ensuring the participant commitment and follow ing-up of non-live elements, and ensuring the all elements of the mix are coordinated [31]. So the flexibility of blended learning appear to become a transition from passive learning to active learning, where the focus of the class shifts from the presentation format to one of active learning. Then students are placed in situations that encourage them to read, speak, listen and think; To offer students an opportunity to be better together or individually; To bring together online and face-to-face class components, and mixing delivery systems, making it possible for students to learn by accessing material in various important modes because students often have different learning styles; To add a human touch to teach so that interactive content allows a high level of interest, accountability, and real judgment can be created; To increase individualization, personalization and relevance so that learners can adjust learning content to the unique needs of different students; and The best offer for students because teachers and students have greater flexibility and accessibility without sacrificing face-to-face contact.

This becomes an approach with effective and low-risk strategies and can meet the challenges of transformational change, where technological developments bring education to a better level (Hodgson in [32]). The composition of the right mix of online and face-to-face 
learning on blended learning is possible to provide broad opportunities for better competency formation, which is based on the results of the analysis of curriculum content in developing the teaching materials used. The materials can be sorted based on the level of difficulty they have, to be packaged in learning with a variety of mixes between online and face to face.

\subsection{Electrotechnical Competence in Blended Learning}

The different backgrounds allow for the different learning characteristics, especially learning styles. The effectiveness of achieving learning objectives can be determined by the learning style[62];[33], which is distinguished as activist, theorist, pragmatist, and reflector [14]. They can be inventoried through real experience, reflective observation, abstract conceptualization, and active experimentation by testing their approach in learning situation [17]. Based on their respective characteristics, that the desire for practical tasks with very little theory, by emphasizing new experiences will be shown by a type of activist. Generally, focus on activities such as games, problem solving, simulation, lots of action and excitement. They can lead and be the center of attention, make ideas without worries about practical constraints, respond to challenges with certainty and take risks, and are happy with team problem solving [64].

While those who wish to rest a lot and travel, read and discuss, are the characteristics of the types of reflector. This type shows the best in activities where there are opportunities to observe and consider. There are strong elements of passive involvement such as listening to a speaker or watching a video to think before acting or contributing, opportunities for research, and problems can be investigated in depth by reviewing what is happening, and asked to make a report by carefully analyzing the situation or problem. Likewise the interaction with other people without the risk of feeling, come forward, and can complete a display without being under pressure [34].

The desire for leaflets to be studied was shown by a type of theorist. This illustrates that the most good learning for this type is from learning activities that form part of the conceptual whole, such as the model for theory, there is time to explore the interrelationships between elements, can explore the theories and methodologies underlying the subject being investigated, stretched intellectually, there are clear, clear objectives for activities, there is dependence on rationality and logic, can analyze situations and then generalize their findings, and they are asked to understand complex situations [35]. While the desire for shortcuts and tips is a characteristic of the pragmatic in learning, namely learning by activities where there is a clear link back to work-related problems. While the desire for shortcuts and tips is a hallmark of pragmatic learning, namely learning with activities where there is a clear link back to work-related problems, the material is directed to techniques that make their work easier to be able to practice what they have learn, and can relate to successful role models, and there are many opportunities to apply what has been learned [36]. The relevance is clear and learning is easily transferred to their work and what is done is practical such as compiling action plans or testing techniques or procedures [37]. It seems the differences that appear primarily in facing the learning situations can be accommodated through a variety of the possible combinations of online and face-to-face learning. The most appropriate and effective combination of online and face-to-face, for individual tasks and learning, will optimize the competency formation [16];[38].

\subsection{Design and Participants}

Our sample was taken as many as 166 participants who are placed in five classes of the electrotechnical course in Electrical Engineering Education Program of the State University of 
Medan. Each of class are learned in the different approach namely Group 1 Online (OL), Group 2 Face to Face (F2F), Group 3 25/75 OL/F2F blended, Group 4 50/50 OL/F2F blended, and 75/25 OL/F2F blended, which envolved 35, 36, 33, 32 and 30 of participants respectively.

\subsection{Tools and Materials}

The learning materials was developed for five different approaches used which encompassed the relation between magnetism and electricity, the production of EMF and current, the faraday's law and electromagnetic induction, the direction of induced EMF and current, Lenz's Law, and the dynamically induced EMF. All of them were validated first by envolving three experts of learning design, electrotechnical teaching material, and instructional media respectively. The elearning facilitation of the electrical engineering education departments with the url addresed: http://jpte-ft-unimed.edu20.org was used in this experiment.

\subsection{Data Collection Tools}

There were two of data collection tools used in this research. The one was the Kolbs' learning style questionnare in browsing the participants' learning style type. And the two was the electrotechnical competency test instruments, which consisted of 30 items of objective test, 20 items of the structured essay tests, and 10 points of the skills assessment. The competency score is determined by combining the three measurements with the maximum measurement weight, each of which is objective test $=30$, test essay 40, skill assessment 30 .

\subsection{Procedurs}

Each of the learning group by involving the different teachers to conduct the experiment. All of the teacher was given the directions to equate perceptions about the implementation of the designed treatment. The learning was done in six time at the same time as learning takes place. The learning styles types of participants are traced using the learning style questionnaires available. And the electrotechnical competencies of all experimental groups were tested simultaneously at the end of the learning activity. The competency data of each group is validated, then sorted based on the group learning and the participant learning style type. Data were tested using 2-Way ANOVA at 5\% significance level with the SPSS Program.

\section{Result and Discussion}

\subsection{Results}

The scores of electrotechnical competencies of all groups with blended learning were higher on average compared to the two groups of full online and full face to face (Table 1).

Table 1. Competencies description based on Learnings

\begin{tabular}{|c|c|c|c|c|c|}
\hline \multirow{3}{*}{ Learnings } & \multirow{3}{*}{$\mathrm{N}$} & \multirow{3}{*}{ Mean } & \multirow{3}{*}{$\begin{array}{l}\text { Std. } \\
\text { Error }\end{array}$} & \multicolumn{2}{|c|}{$\begin{array}{c}\text { 95\% Confidence } \\
\text { Interval } \\
\end{array}$} \\
\hline & & & & Lower & Upper \\
\hline & & & & Bound & Bound \\
\hline Full Online & 35 & 64.287 & 536 & 63.227 & 65.346 \\
\hline Full face to face & 36 & 59.528 & .518 & 58.505 & 60.551 \\
\hline 25/75 OL-F2F & 32 & 79.778 & .549 & 78.693 & 80.862 \\
\hline 50/50 OL-F2F & 33 & 82.750 & .558 & 81.646 & 83.854 \\
\hline 75/25 OL-F2F & 30 & 71.687 & .572 & 70.557 & 72.816 \\
\hline
\end{tabular}


It's provides the highest competency int the same composition between online and faceto-face learning compared to other combinations, which is followed by a combination of 7525 OL-F2F, and 25-75 OL-F2F. When viewed from the competency score based on the type of learning style (Table 2), it appears that the competencies of the pragmatic learning style type group are the highest compared to the other types, followed by activists, theorists, and reflectors.

Table 2. Competences description Based on Learning Style

\begin{tabular}{|c|c|c|c|c|c|}
\hline \multirow{2}{*}{$\begin{array}{l}\text { Learning } \\
\text { Style }\end{array}$} & \multirow{2}{*}{$\mathrm{N}$} & \multirow{2}{*}{ Mean } & \multirow{2}{*}{$\begin{array}{l}\text { Std. } \\
\text { Error }\end{array}$} & \multicolumn{2}{|c|}{$\begin{array}{c}95 \% \text { Confidence } \\
\text { Interval }\end{array}$} \\
\hline & & & & $\begin{array}{l}\text { Lower } \\
\text { Bound }\end{array}$ & Upper Bound \\
\hline Activist & 41 & 72.978 & .501 & 71.987 & 73.969 \\
\hline Theorist & 42 & 69.611 & .452 & 68.717 & 70.505 \\
\hline Pragmatist & 44 & 75.778 & .495 & 74.800 & 76.756 \\
\hline Reflector & 39 & 68.056 & .506 & 67.056 & 69.057 \\
\hline
\end{tabular}

The average competency scores based on the learning style type group are varied (Table $3)$. The competencies of the activist types are higher in the combination of 75-25 OL-F2F, while the theorist and pragmatist types are mixed with the same composition OL and F2F, and the type of reflector in a blend of 25/75 OL-F2F.

Table 3. Competencies Description Based on Learnings and Learning Style

\begin{tabular}{lcccc}
\hline Learnings & $\begin{array}{c}\text { Learning } \\
\text { Style }\end{array}$ & N & Mean & $\begin{array}{c}\text { Std. } \\
\text { Deviation }\end{array}$ \\
\hline Full Online & Activist & 6 & 74.17 & 3.764 \\
& Theorist & 9 & 66.67 & 2.500 \\
& Pragmatist & 9 & 62.22 & 2.635 \\
& Reflector & 11 & 54.09 & 3.754 \\
\hline \multirow{3}{*}{ Full face to } & Activist & 9 & 47.78 & 2.635 \\
face & Theorist & 10 & 57.00 & 2.582 \\
& Pragmatist & 9 & 63.33 & 2.500 \\
& Reflector & 8 & 70.00 & 3.780 \\
\hline \multirow{2}{*}{ F/75 OL- } & Activist & 9 & 77.78 & 2.635 \\
F2F & Theorist & 10 & 70.50 & 3.689 \\
& Pragmatist & 8 & 82.50 & 2.673 \\
& Reflector & 6 & 88.33 & 2.582 \\
\hline \multirow{2}{*}{ F/50 OL- } & Activist & 10 & 78.50 & 2.415 \\
& Theorist & 9 & 86.67 & 2.500 \\
& Pragmatist & 6 & 95.83 & 3.764 \\
$75 / 25$ OL- & Reflector & 7 & 70.00 & 4.082 \\
\hline F2F & Activist & 6 & 86.67 & 4.082 \\
& Theorist & 9 & 67.22 & 2.635 \\
& Pragmatist & 8 & 75.00 & 3.780 \\
& Reflector & 7 & 57.86 & 2.673 \\
\hline
\end{tabular}

It was found that both of the learning approaches and learning styles varieties influenced the competence significantly at the 0.05 level of significance. $F=336,900$, Sig. $\leq 0.05$ and $F$ $=49.037$, Sig. $\leq 0.05$ (Table 4). The interaction between the various of blended learning and the learning styles types are also significantly affect the competence $(F=82.802$; $\mathrm{Sig} . \leq 0.05)$. 
Table 4. Tests of Learnings (Lrn) and Learning Style (LS) Effects

\begin{tabular}{cccccc}
\hline Source & $\begin{array}{c}\text { Type III Sum } \\
\text { of Squares }\end{array}$ & df & Mean Square & F & Sig. \\
\hline $\begin{array}{c}\text { Corrected } \\
\text { Model }\end{array}$ & $24050.226^{\mathrm{a}}$ & 19 & 1265.801 & 132.069 & .000 \\
\hline Intercept & 821673.414 & 1 & 821673.414 & 85730.330 & .000 \\
\hline Lrn & 12915.942 & 4 & 3228.985 & 336.900 & .000 \\
\hline LS & 1409.979 & 3 & 469.993 & 49.037 & .000 \\
\hline Lrn * LS & 9523.335 & 12 & 793.611 & 82.802 & .000 \\
\hline Error & 1399.322 & 146 & 9.584 & & \\
\hline Total & 847975.000 & 166 & & & \\
\hline $\begin{array}{l}\text { Corrected } \\
\text { Total }\end{array}$ & 25449.548 & 165 & & & \\
\hline a. R Squared = .945 (Adjusted R Squared = .938) & & \\
\hline
\end{tabular}

Based on the different test in average scores of the competencies among all of the learning approaches groups showed the significant differences. It seems the reflector type is better taught through the combination of $25-75$ OL-F2F in blended learning by comparing to the others combinations, and the 50-50 OL-F2F of combination provides the better competencies for both of the pragmatist and theorist type. Graphically It is drawn in Figure 1.

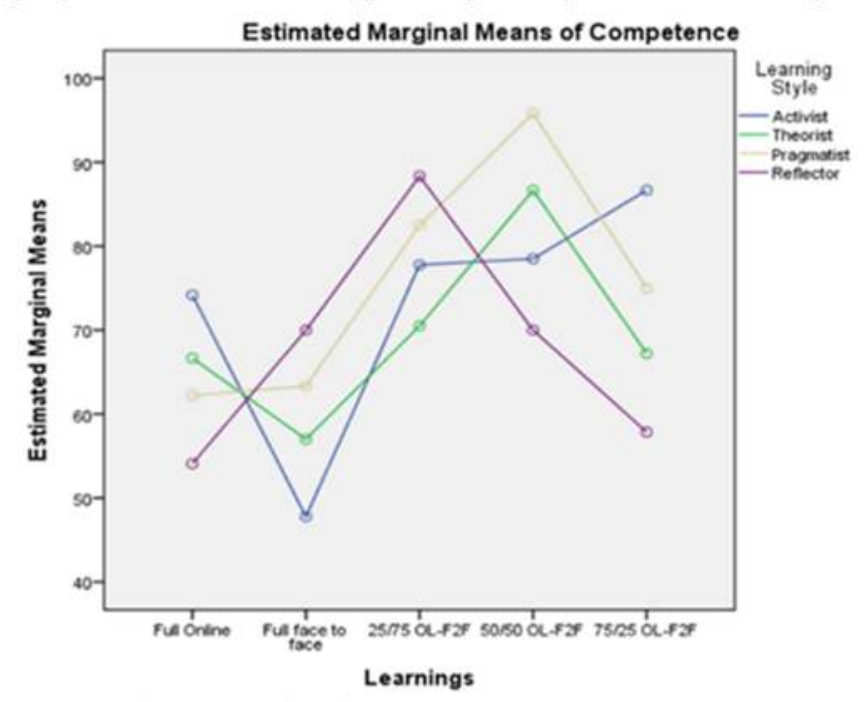

The activist types of learning style appear to be more appropriately taught by a combination of 75-25 OL-F2F, which is shown by the highest competence mean score.

\subsection{Discussion}

The results of this study further emphasize the importance of the right learning form in the various students' backgrounds. The students' competence based on the various learning forms and the learning styles types are diverse. The learning outcomes through online learning and face to face are significantly different. It is in line with the findings of Smith et al (2017) [39] that the results through online learning are higher on average compared to face to face. This is 
possible because of the students can freely access teaching materials at unlimited times and places. This condition gave the wide range of learning opportunities which supported the students by these learning flexibilities. The online learning enables fellow the students to collaborate and interact well as stated by Horspool \& Lange (2012) [40]; [41];[42].

These are different from the findings of [43] who previously claimed that online and equivalent learning activities could be effective for students. These investigation found the groups' competency taught through the blended learning is better than the scores taught by full online and face-to-face learning. This ensures that by combining the online and face-to-face learning provides the better results, which gives the understanding that the combination of the two of them can cover the weaknesses of each of them, in line with the findings of [44] in learning at u-Museum, and Wong, Pine, \& Tsang (2000) [45] in training programs in the hospitality and tourism industry. The similar things were found by [46] on learning in Slovenian Universities which illustrate the variety of backgrounds of students can be overcome by integrating online learning with face-to-face. It can be accommodated as stated by [47], and the difficulties experienced by students in both approaches, online and face to face can be mutually covered as stated by [48].

Each of the activist, theorist, pragmatist, and reflector type has its own characteristics so they needed the different form of learning. The activists type turned out to be more prominent in dominant learning online. This is possible because of the person with an activist type prefers learning activities without the intervention of others. This type wants more practical tasks and very few theories as stated by [49]. The greater portion of online learning allows students to focus on the present and carry out activities such as games and problem solving. Likewise, the theorist type is characterized by the desire for leaflets to be studied, and the pragmatist type who wants shortcuts and tips, but the formation of competencies will be better if they are taught by a balanced combination of the online and face-to-face learning. This shows that both of them have in common that lack of learning can be fulfilled by teachers helps through face-to-face contact with teachers who teach as stated by [50]. While the reflector type tends to give better results when dominant face-to-face, with the characteristic that getting optimal results when accompanied by a lot of rest to go and read and discuss as stated by Rassool \& Rawaf (2008) [51]. This finding is a refutation of the statement that learning styles are myths [13], because it is evident that different types of learning styles when taught with different approaches will provide more optimal results. Thus, learning styles are a real thing to consider in learning.

\section{Conclusion}

The diverse backgrounds, especially learning styles, are important to be considered in choosing the form of learning. The use of blended learning chosen in electrotechnical learning can provide maximum results when the portion between online learning and face to face is distinguished for each type of learning styles. As activists it is better to be given the freedom to learn through online, while reflectors need assistance through face to face. Theoretical and pragmatic types are better given balanced learning between online and face-to-face. However, this research is still limited to some of the competencies of students of the electrical engineering education program in Medan State University so that it still needs to be studied further in a wider scope and field. 


\section{References}

[1] D. Alt, "Science teachers' conceptions of teaching and learning, ICT efficacy, ICT professional development and ICT practices enacted in their classrooms," Teach. Teach. Educ., vol. 73, pp. 141-150, 2018.

[2] J. Blanchette, "Characteristics of teacher talk and learner talk in the online learning environment," Lang. Educ., vol. 23, no. 5, pp. 391-407, 2009.

[3] L. Cuesta Medina, "Blended learning: Deficits and prospects in higher education," Australas. J. Educ. Technol., 2017.

[4] E. Mukama, "The interplay between learning and the use of ICT in Rwandan student teachers' everyday practice," J. Comput. Assist. Learn., vol. 25, pp. 539-548, 2009.

[5] J. Pearson, "Investigating ICT using problem-based learning in face-to-face and online learning environments.," Comput. Educ., vol. 47, no. 1, pp. 56-73, 2006.

[6] C. R. Graham, "Blended learning systems: Defnition, current trends and future directions," in Handbook of blended learning: Global Perspectives, local designs, San Francisco, CA: Pfeiffer, 2006.

[7] B. Czerkawski, "Blending Formal and Informal Learning Networks for Online Learning," Int. Rev. Res. Open Distrib. Learn., vol. 17, no. 3, 2016.

[8] J. Watson, "Blending learning: The convergence of online and face-to-face education," 2012. .

[9] G. Simona, "Optimization of Training Strategies - A Study on Learners' Motivation and Satisfaction," Procedia - Soc. Behav. Sci., vol. 180, pp. 808-813, 2015.

[10] S. Tosun, "The Effects of Blended Learning on EFL Students' Vocabulary Enhancement," Procedia - Soc. Behav. Sci., vol. 199, pp. 641-647, 2015.

[11] A. I. Alducin-Ochoa, J. M., \& Vázquez-Martínez, "Academic Performance in BlendedLearning and Face-to-Face University Teaching," Asian Soc. Sci., vol. 12, no. 3, 2016.

[12] D. Gill, "Effective Blended Learning Techniques," J. Coll. Teach. Learn., vol. 6, no. 2, 2011.

[13] P. A. Kirschner, "Stop propagating the learning styles myth," Comput. Educ., vol. 106, pp. 166-171, 2017.

[14] D. A. Kolb, Experiential Learning. Englewood-Cliffs. New Jersey: Prentice-Hall, Inc, 1984.

[15] D. W. Dwiyogo, "Pembelajaran Berbasis blended learning," 2017. .

[16] L. Price, "Individual Differences in Learning: Cognitive control, cognitive style, and learning style," Educ. Psychol., vol. 24, no. 5, pp. 681-698, 2004.

[17] B. Heffler, "Individual Learning Style and the Learning Style Inventory," Educ. Stud., vol. 27, no. 3, pp. 307-316, 2001.

[18] R. A. Roe, "What makes a copmetent psychologist," Eur. Psychol., vol. 7, no. 3, pp. 192 202, 2002.

[19] M. Haverila, "Factors related to perceived learning outcomes in e-learning," Int. J. Knowl. Learn., vol. 6, no. 4, p. 308, 2010.

[20] J. Martin, "Investigation of Factors Affecting Information Literacy Student Learning Outcomes Fails to Undercover Significant Findings," Evid. Based Libr. Inf. Pract., vol. 6, no. 2, p. 59, 2011.

[21] D. Aixia, "Factors Influencing Learner Attitudes Toward E-learning and Development of Elearning Environment Based on the Integrated E-learning Platform," Int. J. e-Education, eBusiness, e-Management e-Learning, 2011.

[22] S. G. Laster, "Redifining bleneded learning. Blended learning," 2005.

[23] W. Klentien, U., \& Wannasawade, "Development of Blended Learning Model with Virtual Science Laboratory for Secondary Students," Procedia - Soc. Behav. Sci., vol. 217, pp. 706$711,2016$.

[24] E. Deeson, "Effective blended learning practices â “ Edited by Elizabeth Stacey \& Philippa Gerbic," Br. J. Educ. Technol., vol. 41, no. 1, pp. 145-146, 2010.

[25] A. Kitchenham, "Blended Learning across Disciplines," 2011.

[26] A. M. Aasen, "E-Learning as an Important Component in 'Blended Learning' in School Development Projects in Norway," Int. J. Adv. Corp. Learn., vol. 6, no. 1, 2013. 
[27] P. Mihailidis, “(Re)Mix, (Re)Purpose, (Re)Learn: Using Participatory Tools for Media Literacy Learning Outcomes in the Classroom," Action Teach. Educ., vol. 33, no. 2, pp. 172 183, 2011.

[28] H. Singh, "Building Effective Blended Learning Programs," Educ. Technol., vol. 43, no. 6, pp. 51-54, 2003.

[29] D. Woodall, "Blended learning strategies: Selecting the best instructional method," 2010. .

[30] H.-J. H. Chen, "Developing and evaluating SynctoLearn, a fully automatic video and transcript synchronization tool for EFL learners," Comput. Assist. Lang. Learn., vol. 24, no. 2, pp. $117-$ $130,2011$.

[31] J. Hofmann, "Soapbox: Top 10 challenges of blended learning," 2011. .

[32] M. W. N. Eugenia, Comparative Blended Learning Practices and Environments. USA: IGI Global, 2010.

[33] K. Valley, "Learning styles and courseware design," Res. Learn. Technol., vol. 5, no. 2, 2011.

[34] R. Murray-Harvey, "Learning styles and approaches to learning: distinguishing between concepts and instruments," Br. J. Educ. Psychol., vol. 64, no. 3, pp. 373-388, 1994.

[35] W. Revelle, "Hans Eysenck: Personality theorist," Pers. Individ. Dif., vol. 103, pp. 32-39, 2016.

[36] B. Lovie-Kitchin, J., Coonan, I., Sanderson, R., \& Thompson, "Learning Styles Compared Across Health Science Courses," High. Educ. Res. Dev., vol. 8, no. 1, pp. 27-37, 1989.

[37] R. Pashler, H., McDaniel, M., Rohrer, D., \& Bjork, "Learning Styles," Psychol. Sci. Public Interes., vol. 9, no. 3, pp. 105-119, 2008.

[38] M. A. Sultana, S., Khan, S., \& Abbas, "Predicting performance of electrical engineering students using cognitive and non-cognitive features for identification of potential dropouts," Int. J. Electr. Eng. Educ., vol. 54, no. 2, pp. 105-118, 2017.

[39] S. N. Smith, R. L., Flamez, B., Vela, J. C., Schomaker, S. A., Fernandez, M. A., \& Armstrong, "An Exploratory Investigation of Levels of Learning and Learning Efficiency Between Online and Face-to-face Instruction," Couns. Outcome Res. Eval., vol. 6, no. 1, pp. 47-57, 2015.

[40] C. Horspool, A., \& Lange, "Applying the scholarship of teaching and learning: student perceptions, behaviours and success online and face-to-face," Assess. Eval. High. Educ., vol. 37, no. 1, pp. 73-88, 2012.

[41] N. O. Bayraktar, D. M., \& Donmez, "Comparison of Communication Patterns of Students in Online and Face-to-Face Collaborative Learning Environments with Discourse Analysis," Anthropol., vol. 22, no. 2, pp. 265-275, 2015.

[42] X. Shu, H., \& Gu, "Determining the differences between online and face-to-face student-group interactions in a blended learning course," Internet High. Educ., vol. 39, pp. 13-21, 2018.

[43] C. Neuhauser, "Learning Style and Effectiveness of Online and Face-to-Face Instruction," Am. J. Distance Educ., vol. 16, no. 2, pp. 99-113, 2002.

[44] C.-Y. Chen, C.-C., \& Chen, "Exploring the effect of learning styles on learning achievement in a u-Museum," Interact. Learn. Environ., vol. 26, no. 5, pp. 664-681, 2017.

[45] N. Wong, K. K. F., Pine, R. J., \& Tsang, "Learning Style Preferences and Implications for Training Programs in the Hospitality and Tourism Industry," J. Hosp. Tour. Educ., vol. 12, no. 2, pp. 32-40, 2000.

[46] R. Maric, M., Penger, S., Todorovic, I., Djurica, N., \& Pintar, "Differences in Learning Styles: A comparison of Slovenian Universities," Procedia - Soc. Behav. Sci., vol. 197, pp. 175-183, 2015.

[47] B. Boelens, R., Voet, M., \& De Wever, "The design of blended learning in response to student diversity in higher education: Instructors' views and use of differentiated instruction in blended learning," Comput. Educ., vol. 120, pp. 197-212, 2018.

[48] H. Baragash, R. S., \& Al-Samarraie, "Blended learning: Investigating the influence of engagement in multiple learning delivery modes on students' performance," Telemat. Informatics, vol. 35, no. 7, pp. 2082-2098, 2018.

[49] T. Furnham, A., Jackson, C. J., \& Miller, "Personality, learning style and work performance," Pers. Individ. Dif., vol. 27, no. 6, pp. 1113-1122, 1999. 
[50] S. Hendry, G. D., Heinrich, P., Lyon, P. M., Barratt, A. L., Simpson, J. M., Hyde, S. J., ... Mgaieth, "Helping students understand their learning styles: Effects on study self-efficacy, preference for group work, and group climate," Educ. Psychol., vol. 25, no. 4, pp. 395-407, 2005.

[51] S. Rassool, G. H., \& Rawaf, "The influence of learning styles preference of undergraduate nursing students on educational outcomes in substance use education," Nurse Educ. Pract., vol. 8, no. 5, pp. 306-314, 2008. 